\title{
IDEOLOGÍA, CULTURA E IDIOMA EN LAS RELACIONES INTERNACIONALES: EL ESPAÑOL DENTRO DEL TLCAN Stéphan Sberro*
}

RESUMEN: El artículo indaga de qué manera Canadá, Estados Unidos y México podrían establecer un régimen lingüístico para su integración, que no descanse en un laissez faire que significaría la imposición del inglés. Es importante para los tres países preservar un espacio para el español (y el francés) en términos de legitimidad y transparencia. Las autoridades mexicanas deberían conocer más la experiencia canadiense en el terreno de la defensa de la lengua nacional en las instancias internacionales, para unir esfuerzos en aras de un mejor resultado en la resistencia frente a una hegemonía dañina para todos.

sose

ABSTRACT: This article investigates how Canada, the United States, and Mexico could establish a linguistic system for their integration, which does not take a laissez faire approach thereby allowing the dominance of the English language. The three countries must maintain the roles of the Spanish and French language in terms of legitimacy and transparency. Mexican authorities should study the Canadian experience relative to the protection of their national language internationally in order to join forces in the hopes of better results when dealing with a hegemonic force.

PALABRAS CLAVE: Ideología, cultura, español, relaciones internacionales, TLCAN, idioma. KEYWORDS: Ideology, culture, Spanish, International Relations, NAFTA, language.

RECEPCIÓN: 15 de diciembre de 2009.

APROBACIÓN: 25 de enero de 2010.

* Departamento Académico de Estudios Internacionales, ITAM. 
CITAM Derechos Reservados.

La reproducción total o parcial de este artículo se podrá hacer si el ITAM otorga la autorización previamente por escrito. 


\section{IDEOLOGÍA, CULTURA \\ E IDIOMA EN LAS \\ RELACIONES \\ INTERNACIONALES: \\ EL ESPAÑOL DENTRO \\ DEL TLCAN*}

\section{$E_{n}$ los últimos años, la cultura ha} provocado un repunte de interés por parte de los internacionalistas. Desde el principio del siglo XX, el positivismo en las ciencias sociales ha sido enriquecido con teorías "post-positivistas", que recalcan la importancia de los marcos de pensamiento y de las perspectivas, y no solamente de las realidades objetivas. Pero aun dentro de esta corriente, la cultura ha adquirido una mayor importancia en las dos últimas décadas. El artículo seminal de Samuel Huntington sobre el choque de las civilizaciones, ${ }^{1}$ sin apartarse de una visión tradicionalista y estática, introduce la cultura como instrumento y envite de la búsqueda de poder que mueve al mundo. En los años ochenta, otro teórico clásico de las relaciones internacionales, Joseph Nye R., sin rechazar las premisas neo-realistas de esta ciencia, también atribuyó a la cultura un papel importante como instrumento de poder, a la cual calificó de soft power ("poder blando"- el poder no tangible de las ideas).

El propósito de este artículo es contribuir a la reflexión sobre el lugar que ocupa la cultura en las relaciones internacionales. En virtud de que el término cultura es escurridizo, no se pretende definirlo. En realidad, incluso los libros dedicados al tema y la Convención de la UNESCO

* Esta investigación fue posible gracias al ITAM, a la NYU, al gobierno canadiense y a la Fundación Fulbright de Estados Unidos.

${ }^{1}$ Samuel P. Huntington, “The Clash of Civilizations?”, en Foreign Affairs, vol. 72, núm. 3, 1993, pp. 22 у 28. 
STÉPHAN SBERRO

sobre la protección de la diversidad cultural eluden ofrecer una definición precisa.

Para evitar largos y profundos debates teóricos, adoptamos aquí dos estrategias. Primero consideraremos la cultura no solamente como concepto, sino también como práctica, causa y objeto de comportamientos en la política nacional e internacional. En segundo lugar, escogimos el aspecto más tangible y concreto de la cultura, el idioma, y para concretar nuestra reflexión, en este caso el español, como idioma internacional en el marco del Tratado de Libre Comercio de América del Norte (TLCAN). Por ahora, ya se pueden anticipar dos reservas por parte de los internacionalistas ortodoxos en cuanto a este propósito.

La primera objeción atañe al TLCAN. El Tratado no tiene ambiciones políticas explicitas, y menos aún culturales. Sin embargo, la política, en particular la política exterior, desempeñó un papel importante a la hora de iniciar las negociaciones y determinar la forma que tendría el TLCAN y, por ende, la gran región de América del Norte. A su vez, el TLCAN ejerce hoy una influencia sobre la política y la cultura de los tres socios.

La decisión de no tener ni siquiera una unión aduanera, que implicaría una política comercial común y como consecuencia la armonización de la política comercial exterior de los tres socios, fue una decisión política, al igual que la ausencia de una política migratoria común. Por otro lado, la cercanía geográfica, los intereses económicos, la evolución de las tres sociedades, los cambios en el entorno internacional y la misma dinámica del acuerdo amplían su vertiente política y cambian poco a poco las culturas y percepciones de los tres países.

La segunda objeción atañe a la importancia del idioma en las relaciones internacionales, en general, y en el TLCAN, en particular. Se basa en una concepción simplista del idioma, que lo limita a ser considerado solamente un instrumento de comunicación. Un idioma tiene muchas más funciones e implica marcos culturales y perspectivas. Generalmente, las funciones de un idioma se dividen en dos categorías. La primera tiene que ver con la comunicación, pero también existen las funciones simbólicas que no son menos importantes. Así, la comunicación puede ser, entre otras, personal u oficial (la lengua jurídica). Las negociaciones también son parte de la comunicación. Los problemas de "comunicación inter-cultural" son objeto de una cantidad importante de estudios 
teóricos y de consideraciones concretas para el uso de los empresarios, ${ }^{2}$ por ejemplo, y de los internacionalistas. En este rubro, el criterio más válido para usar un idioma es su eficacia para la comunicación internacional y para la protección de los consumidores, por ejemplo, en el caso de un bloque regional.

Las funciones simbólicas del idioma están ligadas a la identidad $y$, por ende, a ideas como democracia y ciudadanía en el campo político. Finalmente, existen zonas grises que no son menos importantes entre la comunicación y el simbolismo. Así, la relación entre lengua y aprendizaje está en el centro de la revolucionara obra sobre psicología infantil de Jean Piaget. De manera que hablar de idioma es, en realidad, hablar de una dualidad fundamental.

Sin embargo, existe otra función del idioma, precisamente como símbolo cultural, elemento constitutivo del individuo (y de la nación) $\mathrm{y}$, por tanto, como parte de su bienestar.

Además, es una realización humana, una riqueza en sí mismo, más allá del uso que se le puede dar, o un "bien primario" de acuerdo con la definición de John Rawls. En este sentido, cualquier idioma es valioso por sí mismo, como muestra de la creatividad y cultura humana, independientemente del uso que se le pueda dar como instrumento. ${ }^{3}$ Por lo que las razones prácticas no pueden ser las únicas en dictar las decisiones lingüísticas y no existe un país que no tenga una política lingüística, explícita o implícita, en el interior y más aún con el exterior. Esta política denota claramente cuál es su proyecto nacional y cómo se propone desarrollarlo.

En este artículo nos abocaremos a estudiar el régimen lingüístico del acuerdo entre tres países que tienen tres idiomas oficiales: español para México; inglés para Estados Unidos, aunque esto no esté mencionado en su Constitución; y francés e inglés para Canadá. Para empezar,

${ }^{2}$ Citemos entre muchos otros los trabajos de David V. J Bell, Power, Influence and Authority: An Essay in Political Linguistics, 1975, London, Oxford University Press.

${ }^{3}$ Omid A. Payrow Shabani, "Language Policy of a Civic Nation State: Constitutional Patriotism and Minority Language Rights", en The Language Question in Europe and Diverse Societies Political, Legal and Social perspectives, 2007, Oxford y Portland Oregon, Hart Publishing, p. 40. 
explicaremos por qué el régimen lingüístico de las relaciones entre los tres socios no sólo es importante en términos de fluidez en la comunicación, sino que también implica relaciones de identidad y de poder, por lo que será interesante observar que los políticos mexicanos son menos sensibles sobre estas cuestiones que sus homólogos en muchos países. También recordaremos cómo no existe nada "natural" en la imposición o desaparición de un idioma, y que el lugar del español en el país es resultado de una política deliberada y drástica por parte de las autoridades coloniales y del gobierno independiente de México.

En la segunda parte, veremos cómo y con qué eficacia España defiende, con un éxito relativo, el lugar del español en el seno de la Unión Europea, antes de remitirnos a la política canadiense, muy activa en general, y en particular dentro del TLCAN. Finalmente, aterrizaremos nuestro estudio con un examen sobre el funcionamiento de uno de los dos organismos oficiales del TLCAN: la Comisión del Medio Ambiente.

Concluiremos con consideraciones sobre la atención que debería prestar México, es decir, sus funcionarios y diplomáticos, para que siempre se le asegure al español el mismo estatus que los dos idiomas oficiales del TLCAN, no solamente para defender nuestra dignidad, sino también nuestros intereses.

\section{La importancia política del idioma}

\section{Lengua y política internacional}

Si los hablantes moldean la lengua, la lengua moldea la mente. Los antropólogos estadounidenses E. Sapir ${ }^{4}$ y L. Whorf, ${ }^{5}$ y antes de ellos Wilhelm von Humboldt, han descrito cómo cada idioma fomenta un esquema de pensamiento y unas estructuras mentales propias. La lengua "se inscribe de forma directa como un motor de pensamiento, de cultura

${ }^{4}$ David G. Mandelbaum (ed.), Selected Writings of Edward Sapir in language, culture and personality, 1963, Berkeley, University of California Press.

${ }^{5}$ John B. Carroll, Language, Thought and Reality, selected writings of Benjamin Lee Whorf, 1966, Massachusetts, Massachusetts Institute of Technology. 
y de civilización". ${ }^{6}$ Aplicando estas ideas al ámbito de las relaciones internacionales, esto significa que las lenguas proyectan el modelo de pensamiento y, por ende, los objetivos de sus hablantes. Los conceptos religiosos, filosóficos, políticos y jurídicos no son equivalentes en todos los idiomas. Se pueden adaptar, pero no son idénticos y reflejan en la traducción las concepciones de las lenguas de acogida. ${ }^{7}$ Si no son traducidos, este fenómeno de digestión no se lleva a cabo y se adoptan o se imponen conceptos tal cual de una cultura a otra. En las relaciones internacionales, al igual que dentro de cada nación, la lengua dominante es la lengua del vencedor, y en esta lucha constante de poder que caracterizan las relaciones internacionales, según la visión neo-realista, "la lengua está en todas partes dentro del poder, y el poder está en todas partes dentro de la lengua". ${ }^{8}$

Desde hace siglos, poetas, políticos y filósofos han afirmado que la lengua se encontraba en el corazón de la identidad nacional. Johann Gottfried von Herder (1744-1803) lo había expresado con su idea del espíritu nacional, Volksgeist. Esta referencia y las consecuencias que tuvo en la política internacional de Alemania y en las relaciones internacionales hasta la Segunda guerra mundial, hace clara la estrecha relación entre proyecto nacional y relaciones internacionales.

Durante mucho tiempo, los debates políticos sobre políticas lingüísticas han sido monopolizados por la cuestión de la construcción nacional. En Europa, el concepto del Estado-nación exigía para la constitución de una nueva comunidad imaginaria, ${ }^{9}$ la eliminación de las minorías lingüísticas. Progresiva en el Reino Unido y en Francia, a partir de la Revolución, tuvo rasgos más dramáticos en los imperios coloniales, y en Alemania, España, Italia y Polonia en los años treinta y cuarenta

${ }^{6}$ Claude Hagège, “Discours d'ouverture”, en Salem Chaker (ed.), Langues et Pouvoir, 1998, Paris, Aix-en-Provence, Edisud-Langues O, p. 14. Hagège cita el ejemplo de la traducción de las nociones evangélicas, y antes de ellas, aristotélicas de sustancia y accidente, que se tradujeron en chino por "lo que se sustenta solo" y "lo que se apoya en algo", lo que hace aparecer una noción de bipolaridad típica de la tradición filosófica china.

${ }^{7}$ M. Bajtin, Walter Benjamin y George Steiner han explorado esta reescritura en el ámbito de la literatura.

${ }^{8}$ Ibidem.

${ }^{9}$ Véase Benedict Anderson, Las Comunidades Imaginarias, 1993, México, Fondo de Cultura Económica. 
STÉPHAN SBERRO

del siglo XX. Este debate sigue vigente en Europa y en el resto del mundo y continúa acaparando gran parte de la atención en los problemas políticos planteados por la diversidad lingüística.

Finalmente, incluso para las minorías nacionales, "afirmar su existencia a través de la preservación de su lengua (y a través de ella, de su cultura), es comprobar una capacidad de acción y afirmar una reivindicación de cambio", dice Anahide Ter Minassian. Lo anterior, se refiere al armenio, cuya afirmación lingüística tuvo consecuencias en el Imperio Otomano y también internacionales con el genocidio de 1915-1917. ${ }^{10}$ Hoy el armenio no es sólo un idioma minoritario dentro de un imperio, es la lengua oficial de un país independiente, con su ejército, y miembro de la ONU, y sus afirmaciones permanecen válidas. En otros términos, el debate sobre las minorías lingüísticas dentro de un Estado-nación y la cuestión de los idiomas hablados por esas minorías, en la arena internacional, tienen algunas similitudes.

Aunque el concepto mismo de cultura sea polémico, es uno de los mayores envites de las relaciones internacionales en general y de la integración regional en particular.

El idioma es una de las características más fuertes y más fácilmente observables de la cultura. Escoger el idioma como objeto de análisis de la influencia cultural no exime de todos los problemas teóricos y prácticos. La lengua es parte de la cultura; sin embargo, también va más allá de ella. Esta relación estrecha y compleja entre lengua y cultura ha sido analizada por grandes pensadores como Benedetto Croce, quien resuelve el problema asimilando la lengua al arte. El antropólogo Claude Levi Strauss emprendió una investigación más profunda sobre esta relación. Para él, la lengua es a la vez el resultado y el origen de la cultura, así como una parte de ella. Además, es una condición para que exista la cultura, pues sirve como instrumento de aprendizaje y trasmisión cultural, y porque está construida con el mismo material que otros aspectos de ésta, como lo son las relaciones lógicas, las oposiciones y las correlaciones. Finalmente, la lengua y la cultura se desarrolla-

${ }^{10}$ Anahide Ter Minassian, "Enjeux d'une Politique de Reconquête Linguistique: Les Arméniens dans L’Empire Ottoman 1853-1914”, en Salem Chaker, 1998, (ed.), op. cit., p. 151. 
ron durante miles de años, una al lado de la otra, dentro de las mismas mentes. ${ }^{11}$

Pero en todo caso, es el testimonio más fácilmente observable y demostrable de los cambios culturales, en comparación con cualquier otro factor cultural como la religión, la arquitectura o el arte en general. El carácter científico de la lingüística, que la opone a todas las otras ciencias sociales y que comparte con las ciencias "duras", como las matemáticas, es otro argumento para escoger la lengua como indicador cultural.

En general, sin embargo, los politólogos e internacionalistas no le dan la importancia que se merece, quizás porque la consideran natural. No todos sabemos de artes pero todos hablamos al menos una lengua. Y a pesar de esto, la situación lingüística de un país, de una región, o en el mundo, no tiene nada de natural. Como en los sectores sociales, económicos y militares, es el resultado de equilibrios de fuerzas y de voluntades políticas. Existen políticas lingüísticas de la misma manera que existen políticas económicas y sociales. Hasta hace muy poco, estas políticas se ejercían esencialmente dentro de las fronteras de los Estados; la situación lingüística mundial se explica por los equilibrios de fuerzas internacionales; en particular, el lugar del inglés, del francés y del español, son resultados de políticas coloniales. Hoy en día existe una nueva vertiente lingüística en la política internacional con la multiplicación de las organizaciones internacionales y regionales.

\section{Lengua y poder}

La definición de una lengua tiene un innegable matiz político. "La lengua es un lugar de poder" según Claude Hagège, el lingüista francés más popular. Este poder es precisamente uno de los tres criterios que la distinguen del dialecto. ${ }^{12}$ Los otros dos criterios de Hagège son,

${ }^{11}$ Claude Levi-Strauss, "Linguistic and Anthropology", en Lucy Burke, Tony Crowley y Alan Girvin (eds.), The Routledge Language and Cultural Theory Reader, 2000, London \& New York, Routledge, pp. 401-409.

${ }^{12}$ Citado en Salem Chaker, op. cit., p. 8-9. 
STÉPHAN SBERRO

por cierto, también eminentemente políticos, y poner en juego el poder; se trata de la existencia de una norma y de ser objeto de reforma.

Existe una distinción aún más clara entre lengua y dialecto. La lengua es un dialecto con ejército, como lo había expresado el yiddishólogo Max Weinreich en 1945. Ahí se mezclan el poder tradicional de corte "neo-realista" y el poder "blando" de Joseph Nye. Los aspectos políticos y sociales son determinantes en la evolución y uso de los idiomas, al lado de factores psicológicos y quizás lingüísticos propiamente dichos. La historia de un idioma refleja y contiene la historia de sus locutores.

La utilización y manipulación de las lenguas, además de los dialectos, para defender algunos intereses políticos, es un fenómeno permanente en la historia. Esta manipulación permitió constituir naciones, destruir otras, colonizarlas, aniquilarlas y revivirlas. La adopción de una lengua oficial siempre fue política tanto en Europa como en sus colonias, y los debates acerca de esto permanecen vigentes, en España por supuesto, pero también en Francia y en el Reino Unido, así como en sus ex colonias. Uno podría escoger Dinamarca, Suecia o Portugal para describir los avatares político-culturales de estas naciones. Fuera de Europa, en los países que adoptaron lenguas europeas, los ejemplos son también múltiples (países africanos adoptando la lengua del colonizador; debates y cambios constitucionales en América Latina y en Estados Unidos; negociación permanente en Canadá). Y los análisis de las políticas lingüísticas fuera de Europa son objetos de los teóricos postcoloniales. ${ }^{13}$

Las relaciones internacionales intentan explicar, y si es posible prever, la proyección e imposición del poder. Esto se efectúa tradicionalmente por la fuerza militar, pero también se han utilizado otros medios como el comercio o la cultura (incluyendo la religión y el idioma). Desde los análisis de Gramsci, sabemos también que la lengua no sólo es un reflejo, sino también un instrumento de poder y un barómetro de sus cambios.

${ }^{13}$ Edward Said, Culture et imperialism, 2000, Paris, Éditions Fayard; Homi Bhabha, The Location of Culture, 1994, London-New York, Routledge; Ngugi wa Thiong'o, Decolonising the Mind: The Politics of Language in African Literature, 1986, London, James Currey Ltd.; Walter Mignolo, The Idea of Latin America, 2005, Massachusetts, Blackwell Manifestos. 
Antonio Gramsci ${ }^{14}$ y Pierre Bourdieu ${ }^{15}$ han tenido un impacto muy profundo en este debate. Uno de sus méritos es el haber sabido vislumbrar no solamente la importancia del poder lingüístico en la sociedad, sino también en el escenario internacional.

Los internacionalistas, también han reaccionado contra la obsesión de la realidad empírica. Las corrientes "reflectivistas" o "postmodernistas" introdujeron un nuevo enfoque que se contrapone a las posiciones "racionalistas" de los realistas y "neo-realistas". El análisis del discurso está avanzando, pero se piensa menos en el idioma como tal. ${ }^{16}$ Sin embargo, se encuentra naturalmente en el corazón de las relaciones entre naciones y, por ende, es parte de un elemento del proyecto de política internacional de cada una de ellas. El idioma puede participar en la necesaria coexistencia entre los enfoques racionalistas y reflexivos. ${ }^{17}$ La globalización y la aceleración de los proyectos de integración regional han acentuado la importancia de formular políticas lingüísticas, tanto nacionales, ante una competencia que viene del exterior, como internacionales, para proyectar sus propias visiones e intereses.

Los franceses hablan desde hace siglos de irradiación cultural (rayonnement culturel); los teóricos estadounidenses, siguiendo a J.

${ }^{14}$ Antonio Gramsci, Grammatica e Lingüistica, 1993, Roma, Editori Riuniti; Antonio Gramsci, El materialismo histórico y la filosofía de Benedetto Croce, 1975, México, Editorial Juan Pablos.

${ }^{15}$ Pierre Bourdieu, Langage et Pouvoir Symbolique, 2001, Paris, Point Essais; Pierre Bourdieu et al., "Quelles langues pour une Europe démocratique?" en Raisons politiques, 2001, núm. 2. Para una idea del pensamiento de Pierre Bourdieu en cuanto a idioma y globalización véase, por ejemplo, Jean-Philippe Mathy, "Refonder l'universalisme, Bourdieu, Balibar et l'exception francaise", en Contemporary French and Francophone Studies, 2008, vol. 12, núm. 3, p. 357-64.

${ }^{16}$ Aquí tenemos un ejemplo concreto de la diferencia entre visiones conceptuales del mundo expresadas por idiomas cercanos, pues son indo-europeos. El francés tiene dos palabras donde el inglés tiene solamente una, language (un galicismo importado en el siglo XII), borrando así una distinción que es uno de los fundamentos de la lingüística moderna de Ferdinand de Saussure. La palabra speech (discurso) puede servir también, pero tiene otra connotación. El español pudo, con otro galicismo, establecer esta diferencia entre lengua y lenguaje.

${ }^{17}$ Sobre el debate entre estas dos visiones, véase, por ejemplo, James Der Derian, "The (S)pace of International Relations: Simulation, Surveillance and Speed", en International Studies Quarterly, vol. 34, 1990, pp. 295-310. 
STÉPHAN SBERRO

Nye, ${ }^{18}$ acuñaron en los años ochenta el concepto de poder blando (soft power) en las teorías de relaciones internacionales para describir la habilidad de un ente político, en general un Estado, para influir cultural o ideológicamente sobre los otros de manera indirecta. Ambas nociones son comparables y describen instrumentos a disposición de los Estados para promover sus intereses sin recurrir a la fuerza armada. ${ }^{19}$ Esta teorización corresponde al uso, siempre más amplio, de estos instrumentos por parte de Francia, de Estados Unidos o del Reino Unido.

Es fácil constatar hasta qué punto el poder armado se vuelve siempre menos utilizable y menos eficaz, mientras el poder cultural, y en particular la influencia lingüística, se vuelven instrumentos eficaces. Ni Serbia en los Balcanes, ni Estados Unidos en el mundo, a pesar de su indisputable poderío militar regional y global, han podido imponer su voluntad únicamente por la fuerza armada. Sin embargo, Estados Unidos sigue ejerciendo una influencia cultural enorme en la élite y los estratos de jóvenes de sus mayores enemigos, como en Irán. La difusión del inglés es una señal clara de esta influencia. Al igual, si Rusia parece haber logrado sus objetivos en Chechenia y en Georgia, su influencia cultural y política está en declive. La victoria de las armas no es suficiente y es temporal, si no está acompañada de una influencia política y cultural. La disminución masiva del uso del ruso, aun en los países eslavos y en el Cáucaso, es una clara señal de una tendencia a largo plazo, que las victorias militares temporales no pueden frenar.

\section{Antecedentes de una política lingüística internacional de México}

Si bien es cierto que los tres idiomas oficiales de América del Norte han sido importados desde Europa, donde permanece su origen y su referencia, en los tres países cada lenguaje impuesto ha sido un elemento impor-

${ }^{18}$ Joseph Nye, Soft Power: The Means to Success in World Politics, 2004, Cambridge, Public Affairs.

${ }^{19}$ También existen los conceptos comparables de "diplomacia pública" y de "mercadeo de las naciones". 
tante de integración de la sociedad y queda ligado inextricablemente a la experiencia de construcción nacional y de proyección internacional. Hoy, las versiones del español, francés e inglés habladas en América del Norte reflejan una experiencia nacional y una cultura propias, aun si se sigue compartiendo un fondo importante de vocabulario, historia y cultura con los países de origen. ${ }^{20}$

No nos ocuparemos aquí de las políticas lingüísticas internas, a menos que éstas tengan una influencia en las relaciones entre los tres países. Así, mientras el español es el segundo idioma más hablado en Estados Unidos, esto no tiene ninguna influencia todavía en las relaciones de este país con México. Por otro lado, el debate lingüístico interno y el bilingüismo canadiense se vuelve un elemento fundamental de su política exterior. Es cierto que el uso del idioma con fines políticos, la construcción nacional y la proyección internacional, alcanzó su mayor grado de desarrollo en Europa; pero, también los tres países de América del Norte saben utilizar el idioma como instrumento de influencia internacional. Es notable el hecho de que en los grandes foros culturales y lingüísticos internacionales, Canadá y Estados Unidos adopten posiciones diametralmente opuestas. El ejemplo más claro es el convenio sobre la protección de la diversidad cultural de la UNESCO en 2006. Canadá, junto con Francia y la Unión Europa, fue la punta de lanza de la iniciativa, mientras Estados Unidos fue el único país que se opuso a ella. ${ }^{21}$

En México, tendemos a descuidar este elemento de nuestra política exterior, confiando en que nuestro peso demográfico es suficiente para eximirnos de pensar en una política lingüística exterior, en particular en América del Norte. Esto es un error. En primer lugar, porque representamos solamente el $20 \%$ de los habitantes de la región, el más pobre. No importa solamente saber que se habla un idioma, también importa quién lo habla y en qué circunstancias. En segundo lugar, si

${ }^{20}$ Véase, Norman Berdichevsky, Nations, Language and Citizenship, 2004, Jefferson NC y Londres, MacFarland and Company Inc Publishers, p. 3.

${ }^{21}$ Israel también votó en contra, pero por razones que tienen que ver más con sus problemas geopolíticos que con su posición sobre la cultura. 
STÉPHAN SBERRO

bien es cierto que el idioma español no está en peligro de desaparecer, puede ser un instrumento útil de proyección de nuestras ideas e intereses si lo sabemos utilizar correctamente. Después de todo, el español es el tercer o cuarto idioma más hablado en el mundo, y México es el primer país hispano-hablante. Esto representa un instrumento político y económico de primera relevancia. Además, si realmente queremos, como parece, diversificar nuestras relaciones económicas y políticas y contar en el escenario internacional, como lo comprueba nuestro afán de ser parte del Consejo de Seguridad de la ONU de manera más activa, el uso del español puede ser un valioso instrumento.

Y para que ocupe el valor que se merece, sería útil observar la experiencia canadiense con el inglés y el francés. Canadá, por razones históricas, ha tenido que cuidar más su política lingüística. La utiliza para proyectar su identidad y, por ende, sus intereses en el escenario mundial, al jugar un papel activo en las instituciones de la ONU, en el Commonwealth y en la Francophonie. También lo hace dentro del TLCAN.

La interacción entre los tres idiomas existe en muchos foros políticos tales como la ONU y la Unión Europea. Sin ambiciones políticas o culturales, el TLCAN no tenía por qué incluir una política lingüística. Es un Tratado y no una organización internacional. El hecho de que esté redactado en los tres idiomas de América del Norte los transforma implícitamente en los idiomas oficiales de la región. Este estatuto se vuelve explícito cuando se menciona que el acuerdo es válido en cualquiera de los tres idiomas oficiales, y que las desavenencias y fallos deben dirimirse en cualquiera de éstos.

Como en todos los aspectos del acuerdo, fuera de los comerciales, esta política lingüística se está dibujando sobre la marcha y de manera implícita. El uso predominante del inglés es natural, dada la predominancia demográfica y, sobre todo, económica de Estados Unidos. La pregunta es saber qué grado alcanzará esta predominancia frente al español y al francés.

En este ámbito, España y los países hispanohablantes son más bien novatos y tienen que aprender de los éxitos y fracasos de sus antecesores. 
Por esta razón la experiencia canadiense en la defensa del francés es importante; primero, porque es, sin lugar a dudas, una lengua muy desarrollada y muy antigua; en segundo lugar, porque se aplica en el mismo espacio en el cual México podría ejercer un poder blando.

A continuación, describiremos la noción de influencia cultural y de política lingüística, antes de abocarnos a la descripción de las reflexiones y acciones canadienses y al estudio de la posible política lingüística del español en los principales foros internacionales. Si para España el estatuto del idioma dentro de la Unión Europea es lo más apremiante, para México la ONU, y sobre todo las instituciones del TLCAN, son los espacios donde puede demostrar su poder político y cultural.

\section{Regímenes lingüísticos y poder dentro de un bloque regional}

México, Canadá y Estados Unidos no interactúan en el vacío ante sus lenguas. Como siempre en el caso de las políticas lingüísticas no heredadas solamente de la situación actual, sino de la historia de su construcción nacional, para los tres países de América del Norte esto significa, primero, la historia de la colonización, la cual duró más tiempo en México.

Las políticas lingüísticas norteamericanas tampoco pueden analizarse independientemente de las políticas lingüísticas de sus lugares de origen, es decir, España, Francia y Reino Unido. Estos tres países poseen una larga e interesante historia de política lingüística y de uso de la lengua con fines políticos. La más mencionada es la de Francia, porque tanto sus políticas como sus resultados fueron más espectaculares. La tradición de intervención estatal que hace del país galo un extremo en el espectro internacional tuvo gran influencia en éstos. En el momento de la Revolución francesa, menos de uno de cada cinco franceses hablaba francés. Todavía antes de la Primera guerra mundial, probablemente eran menos de la mitad en utilizarlo en su vida diaria. Hoy, la totalidad de la población francesa habla el idioma francés. España 
y el Reino Unido no tuvieron que enfrentar situaciones tan difíciles en el pasado en el ámbito lingüístico para su construcción nacional. Sin embargo, ninguno de ellos dudó en desarrollar políticas lingüísticas drásticas, concretamente durante el siglo XIV en el caso inglés. Hoy por hoy, en el Reino Unido y en España este debate está más vivo que nunca, tanto en el interior como hacia el exterior, en relación con los idiomas minoritarios.

Acontinuación estableceremos los antecedentes de una política exterior mexicana activa en materia lingüística. Primero, veremos cómo el español se implantó en México gracias a una política lingüística drástica por parte del colonizador español; luego, tomaremos dos ejemplos actuales. Cabe mencionar que, recientemente, España adoptó una nueva y dinámica política lingüística que importa conocer, pues al compartir la misma lengua, una colaboración con México sería útil aunque no inminente, pues, por ejemplo, por razones propias no existe una colaboración institucional entre Estados Unidos y el Reino Unido en sus políticas de promoción del inglés. Por otra parte, Canadá adoptó una posición activa para defender el francés, idioma oficial dentro del espacio norteamericano que concretó el TLCAN.

\section{La política lingüística del español en América del Norte}

La pasividad relativa de las autoridades mexicanas, si se compara con el activismo canadiense, es engañosa. El presente dinamismo del idioma español, en algunos registros y por el momento, es también engañoso. Podrían dar la ilusión de que la tradición lingüística latinoamericana no se caracteriza por una reflexión avanzada desde el principio, ni una política enérgica en este ámbito. Nada es más erróneo. El español en América Latina siempre ha sido objeto de políticas lingüísticas. En realidad, durante el período colonial, la política lingüística en favor del español fue mucho más importante que en Canadá o en Estados Unidos, que eran colonias de emigración, mientras los españoles llegaban a territorios más poblados, más urbanizados y con idiomas 
más consolidados, en particular porque, contrariamente a los idiomas de los otros países de América del Norte, ya estaban escritos.

En consecuencia, la expansión de la lengua castellana fue un "objetivo geopolítico que se planteó la Corona Española desde el principio de su colonización y mantuvo casi inalterable durante trescientos años". ${ }^{2}$ La escolarización con enseñanza implícita del español y la urbanización son dos factores aculturadores que el Estado presentó unidos para iniciar con ellos la construcción hispanoamericana. Se produjo en el mismo momento con los moros del Reino de Granada, donde se erradicó la lengua árabe y se recogieron los libros escritos en dicha lengua; lo mismo sucedió con los guanches de Canarias, los cuales se aniquilaron al punto de que no se sabe nada de su idioma. En México, también fueron recogidos y destruidos libros y códices prehispánicos. La enseñanza del castellano se hará con más paciencia y pragmatismo, empezando con los hijos de jefes y caciques, algunos de los cuales fueron enviados a España.

En 1530, cuando se da claramente la instrucción de insistir en la enseñanza del castellano, el Reino de España sólo tenía 5.3 millones de habitantes, tres veces menos que Francia, el coloso demográfico de Europa, aunque Francia distaba mucho de tener la homogeneidad lingüística de la España de los Habsburgos. La academia francesa empezó a armonizar el idioma a partir de $1635 .^{23}$

La proporción de hablantes de castellano era aplastante en España; cuatro españoles de cada cinco hablaban el mismo idioma sin variantes dialectales mayores, pues el leonés y el aragonés estaban en vía de asimilación desde el fin de la Edad Media. Sólo un cuarto de la población no hablaba castellano, representada por los catalanes, gallegos y vascos. Hasta el siglo XVIII, España era el conjunto lingüístico más homogéneo de toda Europa. Esta homogeneidad no se debía a la política del

${ }^{22}$ Francisco de Solano, “Aprendizaje y difusión del español entre indios (1492-1820)”, en Langues et Cultures en Amérique espagnole coloniale, 1993, Paris, Presses de la Sorbonne Nouvelle, p. 291.

${ }^{23}$ Alain Milhou, "Les politiques de la langue à l'epoque moderne, de l'Europe à l'Amérique", en Langues et Cultures, op. cit., pp. 15-40. 
STÉPHAN SBERRO

Estado, sino a la demografía y al prestigio de las letras castellanas. Solamente 9\% de los inmigrantes españoles en América no tenían el español como idioma materno. ${ }^{24}$ Pero, paradójicamente, si en España muy temprano se manifestó una conciencia imperial del destino de la lengua castellana, no se hizo nada, contrariamente a lo que pasaba en Francia, ni por los Reyes Católicos ni en la monarquía de los Habsburgos para imponerlo en las regiones periféricas. La política lingüística estaba dirigida contra el árabe. Las cosas cambiaran con los Borbones a partir de 1707, y solamente con Franco se logró la escolarización en castellano de toda la juventud española.

Ya en 1492, antes de la conquista española de América, Elio Antonio de Nebrija, en su gramática del castellano, había expuesto claramente la importancia imperial de la lengua. Nebrija constata la correlación entre la grandeza de las lenguas y de los imperios, tomando los antecedentes del hebreo, griego y latín.

A partir de 1550, varias leyes pregonan la enseñanza del castellano a los indios. En 1560/1570, se estima que la población de México era de tres millones de indígenas, de los cuales solo 5,000 hablaban correctamente español, 30,000 españoles y 25,000 negros. ${ }^{25}$ Se hablaban 125 lenguas en el país que era mucho más diverso que la Costa de Brasil y Paraguay, donde el tupí y el guaraní eran mayoritarios, o el Perú y alto Perú donde el quechua y el aymara eran mayoritarios. El náhuatl también servía de lengua dominante cuando llegaron los conquistadores. El área de estas lenguas de comunicación, náhuatl, quechua y aymara, está hoy más extendida que en el momento de la conquista.

La evangelización fue desde el principio una razón de peso para la asimilación cultural. Se empezó a hablar de la incapacidad de las lenguas indígenas para expresar las verdades de la fe (aunque hubo excepciones como es el caso del dominicano, Domingo de Santo Tomás, admirador del quechua). Además, era el vehículo para extripar ciertas creencias. Fue la opinión del gran conocedor de la lengua y culturas nahuas, la que se

${ }^{24} 3.8 \%$ eran vascos, $1.2 \%$ gallegos, $0.7 \%$ catalanes, valencianos o marroquíes y $2.8 \%$ extranjeros (alemanes, portugueses, flamencos etc.). Ibid., p. 20.

${ }^{25}$ Citado en Alain Milhou, op. cit., p. 23. 
opuso a la traducción de conceptos claves de la fe en lenguas indígenas para marcar la ruptura con el paganismo.

Por eso, la reevangelización en las lenguas vernáculas y el bilingüismo fueron considerados como situaciones transitorias que debían dar lugar a una castellanización general. Sin entusiasmo, pero por convicción y necesidad, los religiosos y curas seculares enseñaron las verdades de la fe en lenguas vulgares. En 1550, 1605 y 1634 se sancionan varias disposiciones legislativas que ordenaron la enseñanza del español a los indios. El argumento religioso cedió poco a poco el lugar al argumento político. En 1770, una cédula real de Carlos III recomendaba: "conseguir que se extingan los diferentes idiomas". No se hizo, porque en América, al igual que en Europa, el despotismo ilustrado no tenía los medios de su política.

En la misma época, pensadores españoles anunciaban las conclusiones que Herder o Whorf citados anteriormente. ${ }^{26}$ Para fray Bartolomé de las Casas, pueblo y lengua son sinónimos, ${ }^{27}$ y "la lengua no es solamente una parte de una nación entre otros elementos tales como la historia, las costumbres o el carácter étnico, es constitutiva de su identidad y hasta de su esencia". ${ }^{28}$

El temor a revueltas de los indígenas, que podrían comunicarse en náhuatl, inclusive con los chichimecas que podrían aprenderlo y así juntar sus fuerzas con los herederos de los aztecas, también estaba explícitamente mencionado. ${ }^{29}$ Los precedentes imperiales azteca e inca eran parte de la justificación para la imposición del español. ${ }^{30}$ En 1599, el uso de idiomas indígenas fue prohibido en las escuelas conventuales. Luego también hubo una política determinada para castellanizar a los

${ }^{26}$ Antropólogos latinoamericanos siguen utilizando la lógica adoptada por Whorf para la lengua y cultura hopis para otras culturas indígenas del continente. Véase, por ejemplo, Alicia Tissera de Molina y Julia Zigaran (eds.), Lenguas, educación y culturas, 2005, Universidad Nacional de Salta, Facultad de Humanidades - que retoma muchas culturas indígenas del sur del continente.

${ }^{27}$ André Saint Lu, "Langue, evangelization et culture chez Las Casas”, Langues et Cultures en Amérique espagnole coloniale, op. cit., pp. 41-5.

${ }^{28}$ Ibid., p. 44.

${ }^{29}$ De Solano, op. cit., p. LXVI.

${ }^{30}$ Ibid., p. LXVII. 
STÉPHAN SBERRO

negros llevados como esclavos al Imperio. Doscientos cincuenta años no fueron suficientes para imponer el español, lo cual fue un objetivo desde el principio. A fines del siglo XVIII se multiplicaron las leyes y medidas para lograrlo.

Finalmente, los gobiernos de la América española, una vez independizados, lograron parcialmente lo que no pudo la España colonial: imponer el español como lengua propia y erradicar los idiomas indígenas. ${ }^{31}$ Este pasado justifica que el español pueda ser considerado un idioma colonial como el inglés, aun dentro de América Latina, como lo defiende el argentino Walter Mignolo, ${ }^{32}$ para quien abandonar el español por el inglés sería solamente abandonar un idioma colonial por otro, con dos diferencias importantes en el ámbito intelectual. En primer lugar, hay más hispanohablantes capaces de leer en inglés, que angloparlantes capaces de leer en español, justificando así el uso del inglés por intelectuales latinoamericanos. Por otra parte, el español es un idioma colonial en desuso en los foros intelectuales internacionales, rebasado por los otros idiomas coloniales en esta área particular. Esta posición extrema sólo traduce el hecho de que hoy imperan dos diferencias mayores con el pasado, en materia de política lingüística del español en América. El mundo está más globalizado que en el siglo XVI y existe un idioma claramente predominante para los intercambios internacionales, en particular en la esfera intelectual: el inglés. La otra diferencia evidente es que hoy las políticas lingüísticas peninsulares y americanas siguen dos caminos distintos. De este lado del Atlántico, el español es la lengua más hablada y se sigue expandiendo, aun en el corazón de Estados Unidos, aunque no sea una lengua de alto estatus, lo que plantea un problema para su perennidad. En cambio, su estatus en España es mas frágil; este último país sigue frágil en cuanto a su supervivencia y percepción, lo que no es

${ }^{31}$ Para citar el caso argentino, "tras la independencia (1810), el lingüicidio se acentuó con la organización institucional de las provincias que impusieron el español como lengua única de enseñanza única en las escuelas", véase Marcelo Javier Aranayo, "Lenguas en peligro de extinción”, en Alicia Tissera de Molina y Julia Zigaran (eds.), Lenguas, educación y cultura, op. cit., pp. 286-7.

${ }^{32}$ Entrevista a Walter Mignolo por Mónica González García: “Towards a Decolonial Horizon of Pluriversality: A Dialogue with Walter Mignolo on and around The Idea of Latin America", en Lucero 2006, 2006, Berkeley, University of California Press, p. 4. 
el caso en los países de América Latina, incluso para las poblaciones no hispanófonas. Desde 1992 tienden a coincidir en algunos ámbitos internacionales.

En América Latina, hasta hace poco no existían políticas lingüísticas externas. Pero las cosas están cambiando y, como en el caso de España, existen dos vertientes, interrelacionadas, a estas políticas. Por una parte, se intenta definir una política de protección y defensa de los idiomas indígenas prehispánicos. Por otra, la globalización, la apertura económica y cultural, la constitución de bloques regionales, rompen el esquema secular que permitía que un americano de habla castellana no necesitara hablar otro idioma para viajar, educarse o trabajar. El TLCAN y los numerosos acuerdos que le siguieron y le seguirán obligan a pensar al lugar del español en el hemisferio occidental. En primer lugar, para la definición de las políticas nacionales; la presión para aprender y enseñar inglés es cada vez más fuerte y entra necesariamente en conflicto con el afán declarado de dar más lugar a los idiomas indígenas. ${ }^{33}$ Por otra parte, uno de los desafíos añejos de América latina se traslada a la política lingüística, con la posible emergencia de un imperialismo lingüístico del inglés. ${ }^{34}$

Interviene un tercer factor que influye en la consecución de políticas lingüísticas más volcadas hacia el exterior: el mayor activismo de España en cuanto a la defensa y promoción del idioma, al fin del régimen de Franco, cuando la hispanidad se quedó en la retórica y la adhesión a la Unión Europea fueron parteaguas para una nueva política de proyección del español, apoyado también en el éxito político, económico y cultural del lugar de origen del idioma. España pasó en algunas décadas de ser uno de los países más atrasados de su continente a ser un modelo tanto para los países vecinos, como para sus ex colonias del otro lado del Atlántico. Para lograr esta proyección, España se inspiró de los ejemplos de otras potencias coloniales: Francia, el Reino Unido y, en menor medida Alemania, con la Commonwealth, la Francophonie, el British Council,

${ }^{33}$ Clare Mar-Molinero, The Politics of Language in the Spanish-Speaking World, 2000, London \& New York, Routledge, p. 200.

${ }^{34}$ Según la expresión de Robert Philipson, Linguistic Imperialism, 1992, Oxford, Oxford University Press. 
la Alliance Française y los Institutos Goethe. Desarrolló dos instrumentos poderosos, los institutos Cervantes y las Cumbres ibero-americanas. A esto finalmente cabe agregar la red de academias de lengua española en España y América Latina, que también ofrecen un instrumento de presión en los foros internacionales. Pero, contrariamente a lo que pasa en el caso del inglés y más aún del francés, España no puede ni desea ser el principal centro del poder lingüístico del español. Más que cualquier idioma de comunicación internacional, el español es un idioma pluricéntrico. ${ }^{35}$ Esto constituye un tercer argumento a favor de una mayor conciencia de la política lingüística internacional para América Latina.

\section{El español en Europa hoy}

En el caso del español en España, existen en realidad tres campos donde se ejerce la política lingüística.

- La del español/castellano ${ }^{36}$ frente a los otros idiomas nacionales, catalán, euskera, gallego y ahora incluso aragonés, bable o leonés.

- La defensa y promoción del español dentro del bloque regional europeo.

- La defensa y promoción del español en el mundo, las Américas e instituciones internacionales en particular.

Durante siglos, este tercer aspecto fue el más importante, si no el único de la política lingüística española que se mostró abierta hacia los idiomas minoritarios de la península y no se preocupó del español en el resto de Europa. El prestigio de su literatura y de su imperio bastaba para asegurarle un lugar. Hoy por hoy, el orden de prioridad está trastornado. La situación dentro de la península da lugar a acerbos debates. España es uno de los países más estudiados y ejmplares en cuanto a

${ }^{35}$ M. Clyne, Pluricentric Languages, Differing Norms in Differing Nation, 1992, Berlín, Mouton De Gruyter.

${ }^{36}$ J. Mondéjar Cumpián, 'Castellano'y 'español', dos nombres para una lengua, 1981, Granada, Don Quijote. 
políticas lingüísticas y respeto de las minorías lingüísticas. ${ }^{37}$ La importancia de la integración europea le da, naturalmente, el segundo lugar en el orden de las preocupaciones al papel del idioma español en Europa. Este aspecto es el que nos ocupa en el marco de esta reflexión.

Existe también, por supuesto, una estrecha relación en el desarrollo de las dos primeras políticas. Por ejemplo, el catalán, hablado por 7-10 millones de personas según las estimaciones en Europa, sería una lengua media en la escala europea, por encima de la mayoría de las 23 lenguas oficiales de la UE. Los catalanes han intentado adquirir algunos derechos, como el de utilizar el catalán en sus comunicaciones bilaterales con la Comisión Europea. El estatuto progresa, pero, para que se vuelva un idioma oficial, primero el gobierno central español lo habría de proponer a sus colegas.

En realidad, el lugar del español en América Latina y en el mundo sirve hoy de argumento para los objetivos de consolidación en España y en Europa

La suerte del idioma español en Europa también está influenciada por las políticas europeas en materia lingüística. Existe una política europea de protección y promoción de los idiomas minoritarios con:

- La Carta de las lenguas regionales desde 1981.

- La oficina europea para los idiomas menos utilizados en Dublín.

- La red Mercador de observación de la evolución de las políticas lingüísticas.

También existen proyectos más horizontales que tienen un efecto de fomento del uso y aprendizaje de los idiomas más pequeños, como

${ }^{37}$ Citemos, entre muchas referencias de libros y artículos que se publican constantemente sobre la cuestión lingüística dentro de España, a Clare Mar-Molinero, The Politics of Language in the Spanish Speaking World, op. cit.; Charlotte Hoffamnn, "Language Planning at the Crossroads, the Case of Contemporary Spain" y Audrey Brassloff, "Centre-Periphery Communication in Spain: the Politics of Language and the Language of Politics", ambos en Charlotte Hoffmann (ed.), Language Culture and Communication in Contemporary Europe, 1996, Clevedon, Multilingual Matters. Para el aspecto más polémico del tema, véanse los artículos de filósofos como Fernando Savater, “Con lengua o sin lengua?", en Nexos, 2008; o la entrevista de George Steiner, "Yo intento fracasar mejor", en El Pais, 24 de agosto de 2008. 
STÉPHAN SBERRO

LINGUA ERASMUS, SOCRATES o el Consejo Europeo del Idioma (European Language Council) con redes temáticas que examinan las cuestiones de idiomas en las instituciones europeas de educación superior.

Finalmente, existen varias directivas europeas acerca de los idiomas. La más notable es la de 1977 sobre la enseñanza del idioma materno para los hijos de inmigrantes. Así, la base de la política europea, que atañe al español, es la estricta protección de la diversidad lingüística y de los idiomas oficiales de los Estados miembros.

Sin embargo, la evolución concreta apunta hacia la emergencia de tres idiomas principales de trabajo: alemán, inglés y francés. En realidad el idioma de comunicación más utilizado por mucho es el inglés, con un papel importante para el francés, lengua de las tres ciudades sedes principales de la Unión (Bruselas, Estrasburgo y Luxemburgo), así como único idioma de trabajo del Tribunal Europeo de Justicia. En este caso, España, como todos los Estados miembros menos el Reino Unido, no puede y no quiere descansar en las reglas oficiales, sino ser vigilante. En este sentido, para España y su idioma, el futuro es más incierto en el viejo continente que en América, donde se ubica ciertamente un futuro del idioma mucho más alentador en términos de proyección nacional, regional e internacional que el de la casi totalidad de los idiomas oficiales de la Unión Europea. Pero en este futuro participan diecinueve países más, entre los cuales México es el más importante, por lo menos en términos demográficos. Nuestro desempeño dentro del TLCAN tendrá, por ende, una importancia singular. A continuación veremos cómo, si en el pasado nuestra política lingüística estaba determinada desde España, hoy este país no puede ser una referencia. Vimos que sus prioridades en materia de política lingüística han cambiado con su entorno geopolítico. Compartir un mismo idioma hace natural la cooperación para lograr objetivos comunes. Nada impide, tampoco, que saquemos lecciones de las políticas españolas en materia de multilingüismo y defensa del idioma dentro de un bloque regional. Sin embargo, no podemos olvidar que España busca proyectar un poder e intereses propios que son distintos de los nuestros y que el marco natural de desarrollo de su política lingüística es Europa. El nuestro es América y, desde hace quince años, 
América del Norte. Por ende, tenemos que definir nuestra política lingüística internacional en el marco de nuestra relación con Estados Unidos y Canadá. Este último país puede ser un marco de referencia útil y podemos, sin lugar a dudas, compartir experiencia y entablar una cooperación.

\section{La proyección del francés por Canadá en América del Norte $e^{38}$}

Canadá y México son distintos culturalmente, en cuanto al peso demográfico, la situación económica de sus poblaciones y también por la relación que mantienen con su idioma. Por ende, no es sorprendente la diferencia en las políticas lingüísticas internas conducidas por México y por Canadá para enfrentar sus problemas.

Sin embargo, en cuanto al aspecto de la política lingüística dentro de América del Norte, el comportamiento canadiense no deja de ser relevante para establecer una política lingüística propia de México. Para empezar, Canadá es oficialmente bilingüe y es el rasgo fundamental de su política lingüística, mientras que en México, a pesar del reconocimiento de las lenguas indígenas, el español tiene el monopolio en cuanto a estatuto oficial federal (aunque el español no es constitucionalmente lengua oficial en México, un rasgo que compartimos con Estados Unidos). En Canadá, el inglés y el francés tienen exactamente el mismo estatuto al nivel del gobierno federal, del Parlamento y de la justicia. En esta reflexión nos abocaremos a la defensa y promoción del francés en América del Norte, pues el inglés, por ser el idioma oficial de Estados Unidos, no necesita ser objeto del mismo voluntarismo. Tampoco hablaremos de la defensa de los idiomas indígenas en México ni en Canadá, pues este aspecto no es, todavía, relevante regionalmente.

${ }^{38} \mathrm{El}$ presente artículo, en particular esta parte y la final, se pudo realizar con el apoyo del gobierno de Canadá, que permitió realizar entrevistas personales con responsables de la política lingüística nacional, provincial de Québec, y de la Comisión para la Cooperación Ambiental en Montréal. También agradezco al Centro de Estudios de la Unión Europea de la Universidad de Montréal. 
Queda claro que hasta ahora las diferencias predominaron sobre las similitudes y que la sensibilidad de los dos países frente a su afirmación lingüística en general, y, en América del Norte en particular, son evidentes. Los hablantes del español no tienen, como los francófonos de Canadá, el sentimiento de ser una minoría que tiene la responsabilidad de luchar por su supervivencia lingüística dentro de su país y de su región natural.

Sin embargo, también existen analogías y sobre todo intereses comunes en cuanto a la defensa de los derechos lingüísticos de las poblaciones canadiense y mexicana en el ámbito internacional y en particular en su región, América del Norte, así como en la promoción de los intereses propios de los dos países frente a la arrolladora potencia de la cultura estadounidense, conducida por el inglés.

Existen, además, similitudes entre el español y el francés en América del Norte que permiten entablar una colaboración más estrecha. Son dos lenguas oficiales que expresan y reflejan una diferencia con la cultura anglosajona predominante al norte del continente. Son dos lenguas minoritarias en la región, en comparación con el inglés, lo que permite destacar y proteger la identidad de los dos países frente al ingente poder cultural de Estados Unidos. Son dos lenguas con estatuto internacional, lo cual que implica una sensibilidad particular. Finalmente, son dos lenguas latinas con una lógica similar y, relativamente, de fácil aprendizaje. $^{39}$

A pesar de su estatuto extremadamente minoritario (con un máximo de $3 \%$ de la población de América del Norte que habla francés), o quizás gracias a esto, los francoparlantes de Canadá han emprendido, desde los albores de la integración regional, una reflexión sobre el lugar de su idioma, la forma de protegerlo y la posibilidad de consolidarlo en la región. La situación del español parece mucho más sólida. Sin embargo, la presencia del inglés es arrolladora y México podría sacar provecho de la experiencia canadiense en materia de protección de sus derechos lingüísticos.

${ }^{39}$ Desde el punto de vista lingüístico, Québec, y por ende Canadá, es parte de América Latina. El debate queda abierto. 
En Canadá existe una política explícita que apunta a promover en el país "un sentimiento de pertenencia y una identidad distinta en aras de reforzar la unidad nacional". ${ }^{40}$ Esta política se tradujo, primero, en el Acta de los Idiomas Oficiales de 1969, enmienda que hace del inglés y del francés los dos idiomas oficiales del país con derechos, estatus y privilegios idénticos para su uso en el Parlamento y el gobierno de Canadá.

Pero poco después de la adopción de la política oficial del bilingüismo, se adoptó también una política de multiculturalismo para reconocer los derechos de otros grupos lingüísticos que, después de los dos "pueblos fundadores", contribuyeron a la edificación de Canadá. Para W. Kymlicka, ${ }^{41}$ la tensión entre bilingüismo y multiculturalismo sólo es aparente, pues la política de multiculturalismo en un marco bilingüe sirvió para separar el idioma del origen étnico. También permitió hacer implícito que reconocer dos idiomas solamente por encima de otros, indígenas o de inmigrantes, no era una forma de dar prioridad a estas dos etnias y sus modos de vida. En Canadá el reconocimiento de los derechos culturales individuales es una negociación constante que exige el carácter altamente diverso de la sociedad canadiense. Lo interesante es que estas decisiones, aun sancionadas por los tribunales, son consideradas como un compromiso político, no un principio. En Canadá se establece una distinción entre los derechos constitucionales, que son un principio, y los derechos lingüísticos, que se basan en la historia política de los dos pueblos fundadores, y así los canadienses establecen una distinción entre derechos humanos y derechos lingüísticos. ${ }^{42}$ Este pragmatismo se explica por el carácter excepcionalmente diverso de la sociedad canadiense, pero también de sus élites, que son también diversas y expuestas a varias culturas y varios idiomas.

Aunque esta política puede solucionar conflictos inmediatos eficazmente, no aporta una solución de fondo a las dos mayores injusticias

${ }^{40}$ René Lemieux y Michael Rossignol, "Diversité linguistique et culturelle dans un contexte d'intégration économique des Amériques", BP-453F Programme des services des dépot del gobierno de Canadá, http://dsp-psd.tpsgc.gc.ca/Collection-R/LoPBdP/BP/bp453-f.htm.

${ }^{41}$ Will Kymlicka, Finding Our Way, 1998, New York, Oxford University Press.

${ }^{42}$ Citado en Omid A. Payrow Shabani, op. cit., p. 50-1. 
STÉPHAN SBERRO

lingüísticas en el país, en cuanto a la relación del francés con el inglés. En 1977, la Ley 101 de política lingüística fue el resultado de una reflexión que había madurado a lo largo de toda la dolorosa historia de la provincia. La "Carta Canadiense de los derechos y libertades", adoptada por el Parlamento en 1982, retomó la ley constitucional que se remontaba a 1867 y que otorga al francés y al inglés el mismo estatuto en las instituciones federales, el Parlamento y en la provincia del Nuevo Brunswick. En 1988 fue adoptada la Ley sobre las lenguas oficiales. El respeto al bilingüismo también está incluido en la "Ley canadiense sobre los derechos humanos".

Este aparato legislativo permitió preservar y reforzar la posición del francés en Canadá, pero existen algunos bemoles. La "francización" de las empresas tuvo que retroceder para evitar que las principales firmas industriales quebequenses huyeran a Ontario. Ante esta amenaza, que empezaba a concretarse, se exentó de la "francizacion" obligatoria a las sedes sociales y a los centros de investigación de las empresas. Así, las tareas más elevadas siguen realizándose solamente en inglés, mientras el uso del francés sólo es obligatorio para las tareas subalternas. Queda pendiente ver cómo evoluciona concretamente la "francización industrial" y si los "certificados de francización" significan algo realmente. ${ }^{43}$

Estos problemas, y la promoción interna del bilingüismo, hacen que Canadá suela estar activo en los debates internacionales acerca de los derechos lingüísticos, para plantear la cuestión de los idiomas en los foros internacionales. Sin embargo, en dos de los foros más importantes, Canadá escogió adoptar un perfil más bajo. En los debates sobre la excepción cultural en la UNESCO, los derechos lingüísticos no figuran claramente. Canadá no encontró aliado dentro del mundo francófono y prefirió concentrarse en los debates más concretos de este tema, sobre la producción cultural. Sólo permanece explícita la excepción a favor de un idioma minoritario, y aun así el estatuto del francés en América del Norte se encuentra abierto a la interpretación. Si bien es amplia-

${ }^{43}$ Robert Chaudenson, "Politique et aménagement linguistiques. Des concepts revisités à la lumière de quelques expériences", en Juillard C. y Calvet L. J. (eds.), Les politiques linguistiques, mythes et réalités, 1996, Beyrouth, FMA, AUPELF-UREF, p. 115-26. 
mente minoritario en el continente, e incluso en Canadá, es ampliamente mayoritario en Québec.

Los temas del estatuto lingüístico y de la protección de la soberanía lingüística también fueron eludidos en las negociaciones del TLCAN, aunque no el de la excepción cultural. Dada la dificultad de defenderla en un foro como la UNESCO, la decisión era de preverse. La ausencia de propósitos políticos y de la voluntad de integrarse más allá del comercio hizo el debate difícil. Sin embargo, hubiera sido posible. Más bien, la indiferencia de Canadá (y México) y la expectativa de un rechazo firme por parte de Estados Unidos, explican la omisión de los negociadores canadienses, si hubieran tenido la voluntad o sensibilidad para hacerlo, lo que es difícil saber.

Para Pierre Georgeault, ${ }^{44}$ el gobierno canadiense de la época, liberal, no tenía un interés en esta cuestión, y el gobierno conservador que le sucedió menos aún. Un solo partido, el partido québécois, hubiera podido insistir sobre esta cuestión, pero por una parte es imposible que este partido defienda los intereses federales, y por otra, Québec, más que otras provincias, tenía un interés político particular en el éxito de las negociaciones, tanto desde el punto de vista económico, como porque le permitía escapar de la relación exclusiva con el resto de Canadá. Finalmente, ningún político canadiense emitió un juicio sobre las reglas que debería, eventualmente, respetar el TLCAN para preservar el lugar de sus tres idiomas oficiales.

Sin embargo, el gobierno canadiense dio algunos pasos hacia una política lingüística en el marco del TLCAN. En 1997, René Lemieux y Michel Rossignol, de la división de los asuntos económicos del gobierno de Canadá, publicaron un informe de reflexión sobre la "diversidad lingüística y cultural en el contexto de la integración económica de las Américas". ${ }^{45}$ Este informe destacaba varios hechos importantes. Primero, el hecho de que Canadá se había asegurado de excluir los servicios culturales del alcance del TLCAN.

${ }^{44}$ Entrevista a Pierre Georgeault, director de la investigación y administración, Conseil Supérieur de la Langue Françoise, 17 de julio de 2008.

${ }^{45}$ René Lemieux y Michael Rossignol, "Diversité linguistique et culturelle dans un contexte d'intégration économique des Amériques", BP-453F Programme des services des dépot del gobierno de Canadá, http://dsp-psd.tpsgc.gc.ca/Collection-R/LoPBdP/BP/bp453-f.htm. 
STÉPHAN SBERRO

Segundo, que la experiencia del país en materia de defensa y promoción de la diversidad lingüística y cultural le otorgaba un papel principal en el marco de la posible ampliación del TLCAN a todo el continente. Tercero, los parlamentarios pueden desempeñar un papel importante en este ámbito, en particular en el marco de la conferencia parlamentaria de las Américas. Se contemplaba la creación de una red parlamentaria que serviría como foro de discusión a nivel de las Américas. Así, sin expresar una política lingüística, el documento de reflexión oficial planteaba medidas de protección, incluyendo una cláusula de exención cultural para preservar la diversidad lingüística y cultural. Es notable que durante la cumbre de de las Américas, (Québec, 2002), Louise Baudouin haya insistido para que los textos de trabajo aparezcan también en francés. Sin esta insistencia, los trabajos en la única capital provincial francófona de América del Norte hubieran estado únicamente en inglés y español (a prueba la ausencia del portugués como lengua de trabajo). Finalmente, en el mismo 2002, se organizó el primer "seminario interamericano sobre la gestión de las lenguas". ${ }^{46}$

Estados Unidos, por su parte, mira con gran desconfianza cualquier justificación política o cultural para condicionar el libre comercio. ${ }^{47}$ Además, aun en caso de que exista un problema real, la cultura estadounidense suele ser renuente ante demasiada reglamentación. Pero esta renuencia de principio se vuelve rigidez. Para Georgeault, los industriales y empresarios serían probablemente menos renuentes a observar reglas lingüísticas si esto significara un mayor acceso al mercado.

El abandono del ALCA significa una mayor dificultad para evitar la supremacía del inglés en las relaciones hemisféricas, pues la nueva estrategia de Estados Unidos es favorecer negociaciones bilaterales en las cuales pueden presionar más fácilmente a sus socios, que individualmente tienen menos peso, y valerse de los antecedentes, en particular el del

${ }^{46} \mathrm{http} / / /$ www.cslf.gouv.qc.ca/cslfseminairefr.asphttp://www.cslf.gouv.qc.ca/cslfseminairefr. asp (la página de internet no está disponible, por lo que no pude hacer la cita correctamente)

${ }^{47}$ Véase el artículo completo de Christopher M. Bruner, "Culture, Sovereignty, and Hollywood: UNESCO and the Future of Trade in Cultural Products", en N.Y.U. J. International Law \& Politics, vol.351, núm. 40, 2008, donde se contrastan las distintas visiones de Estados Unidos, Canadá y la Unión Europea. 
TLCAN, para rechazar que la protección de todos los idiomas oficiales de los socios sea un elemento de la negociación. Tercera dificultad nueva, el estancamiento del ALCA se debe en gran parte a la renuencia de Brasil, el país que más fácilmente (por su peso y su idioma también único en las Américas) hubiera podido ser el aliado natural del francés, pero también del español.

\section{La política lingüística internacional de América del Norte}

\section{El TLCAN, la teoría}

La necesidad y los beneficios de una mayor conciencia lingüística internacional son más evidentes para México que para cualquier otro país de América Latina. En primer lugar, es el país es donde más se habla español en el mundo. Nuestro peso demográfico nos impone obligaciones y ofrece oportunidades. Por esta razón, la diplomacia mexicana desea ser más activa en los foros internacionales, en particular en la ONU. En segundo lugar, México es el primer país latinoamericano en tener un proyecto regional con Estados Unidos y Canadá. Este proyecto un día puede arrastrar al resto del continente y estamos en una posición privilegiada para establecer las reglas del juego en materia lingüística.

Para los europeos, un estatuto lingüístico venía naturalmente en el proyecto de integración regional. Vimos cómo no fue así en el caso de América del Norte. La explicación no estriba en el carácter lingüístico o cultural propio de tal o cual continente, sino del carácter de los acuerdos que se negocian.

Contrariamente a lo que se podría pensar, dadas las diferencias fundamentales entre los dos proyectos de integración regional, su estatuto lingüístico no es tan distinto. El de la Unión Europea tiene su origen en la igualdad afirmada de las cuatro versiones lingüísticas del Tratado de Roma (alemán, francés, italiano y neerlandés). Pero concretamente, sólo está explicitado en un artículo del Tratado y una ley del consejo de ministros europeos del año siguiente, en 1959. El Consejo de minis- 
tros decide la política lingüística común, por unanimidad, y medio siglo después nada ha cambiado. La ley de 1959 establecía una distinción entre idioma oficial e idioma de trabajo, sin especificar más. Cincuenta años y diecinueve idiomas oficiales después, no se ha avanzado más.

Así que, a pesar de la complejidad legal del aparato jurídico europeo, sus reglas lingüísticas son tan breves como las del TLCAN. En ambos casos, se trata de un único artículo que reconoce que todos los idiomas, en los cuales se tradujo oficialmente el Tratado, son oficiales. En el TLCAN, como en la UE, las instituciones tienen la responsabilidad de resolver la aplicación concreta de esta regla general. Los procedimientos de resolución de disputa son también sometidos a esta regla en ambos casos. Las únicas instituciones trilaterales del TLCAN, la Comisión para el Trabajo y la Comisión del Medio Ambiente, adoptaron explícitamente, no sólo implícitamente, la regla del trilingüismo.

\section{La realidad del funcionamiento lingüistico del TLCAN}

Contrariamente a lo que se hubiera podido intuir, dado el peso del idioma inglés en el mundo, y en particular en América del Norte, y por el relativo desinterés del gobierno mexicano para asegurar el lugar del español durante las negociaciones del TLCAN, se está instalando un verdadero trilingüismo en América del Norte. Este trilingüismo es evidente en la vida diaria con el aumento significativo del etiquetaje en los tres idiomas.

Las reglas están estrictamente respetadas en cuanto a la traducción de los documentos y declaraciones oficiales. Los sitios de Internet están también en los tres idiomas; las cuatro reuniones anuales del comité público conjunto, encargado de apoyar a los gobiernos en sus decisiones y de contribuir a la armonización de las políticas ambientales, también se benefician con una traducción simultánea, y todos sus documentos de trabajo, así como sus recomendaciones y publicaciones, están traducidos.

Sin embargo, nos pareció interesante ir mas allá y ver cómo funcionaba una de las dos instituciones oficiales del TLCAN, la ya mencionada 
"Comisión para la Cooperación Ambiental", ${ }^{48}$ ubicada en Montréal. ${ }^{49}$ La otra institución oficial, la Comisión del Trabajo, ubicada en Dallas, funciona sobre los mismos principios. Pero, al estar ubicada en Montréal, en donde se habla francés, con más reuniones y produciendo muchos más documentos técnicos y reuniones que la Comisión del Trabajo, la Comisión Ambiental me pareció más relevante para sacar algunas conclusiones generales sobre el régimen lingüístico actual y deseable en América del Norte.

En este ámbito, más político a nivel ministerial, se respeta un estricto trilingüismo. Sólo los ministros y sus alternos tienen el poder de emitir resoluciones. Sus reuniones se desenvuelven en los tres idiomas, con interpretación y traducción simultánea de todos los documentos oficiales debatidos. Para encargarse de esta traducción se designa un "redactor en jefe" en cada uno de los tres idiomas.

Sin embargo, cuando uno se traslada del más alto nivel al funcionamiento diario de la Comisión, el "estricto" trilingüismo se matiza. En primer lugar, comparando con la experiencia europea, es extraño constatar que los agentes de esta Comisión no tienen la obligación formal de hablar al menos otro de los idiomas oficiales de América del Norte. Cabe notar que estos agentes, contrariamente a lo que pasa en la Unión Europea, no son ni funcionarios, ni diplomáticos, lo que también puede explicar la ausencia de esta condición. Desde el director ejecutivo, nombrado políticamente por los tres gobiernos, ${ }^{50}$ hasta las secretarias, los contratos son de un máximo de tres años, aunque son renovables en algunos casos. Muchos agentes del secretariado y sobre todo muchos expertos, no pueden expresarse en los tres idiomas, y no tienen incentivos para aprender rápidamente otro u otros dos idiomas. Aun así, pudimos constatar que el francés y el español se hablan con frecuencia en las relaciones informales y que la mayoría de los trabajadores

${ }^{48}$ El sitio web oficial de la Comisión para la Cooperación Ambiental es: http://www.cec. org/home/index.cfm?varlan=espanol.

${ }^{49}$ Entrevisté a varios agentes de esta institución, de las tres nacionalidades, y agradezco la paciencia de Jeff Stoub, el encargado de difusión, prensa y relaciones públicas por sus explicaciones.

${ }^{50} \mathrm{El}$ secretario es un cargo rotativo. Cada tres años, el gobierno en turno propone una lista de candidatos y los tres gobiernos escogen a uno. 
STÉPHAN SBERRO

se expresan con fluidez en dos o tres de los idiomas oficiales de la región. Pero la situación cambia cuando se llega al meollo de la misión de la institución. En las reuniones de trabajo, el inglés es casi siempre el único idioma utilizado y no existen traducciones simultáneas en los dos otros idiomas. Los funcionarios de enlace que conforman los grupos de trabajo entre los tres gobiernos y que tienen teleconferencias, al menos cada dos semanas, se expresan casi exclusivamente en inglés.

Las actividades relacionadas con el peritaje de la agencia tampoco siguen una pauta rígida. Para los proyectos, se contratan a expertos reconocidos en sus países para el tema en cuestión; cada experto escoge su idioma. Una vez más, el lugar del inglés es preponderante. Existen muchos más expertos de habla inglesa en Estados Unidos y Canadá, por el peso demográfico natural, y un mayor nivel de estudios. A esto se agrega el hecho de que muchos francoparlantes y, sobre todo hispanoparlantes, prefieren escribir en inglés, no solamente para ser mejor entendidos, sino porque conocen mejor los términos técnicos especializados en inglés que en su propio idioma. Las reuniones relacionadas con los proyectos y los talleres técnicos se desenvuelven de forma pragmática. Los participantes pueden solicitar una traducción, pero no es simultánea. Por ende, se solicita cada vez más que los científicos mexicanos, y más aún los canadienses francoparlantes, se expresen en inglés; no obstante, no todos lo hacen con soltura. A este sesgo en favor del inglés se agrega el hecho de que, para preparar los talleres especializados, se preparan documentos de trabajo para los cuales no existe la obligación de un estricto trilingüismo, pues no están destinados al público en general, sino a los expertos. Si se emiten comunicados de prensa, en cambio, sí se traducen a los tres idiomas. En consecuencia, estos documentos se redactan casi siempre exclusivamente en inglés.

Flexibilidad y economía ${ }^{51}$ parecen ser las principales líneas directoras del régimen lingüístico de la Comisión.

${ }^{51}$ La Comisión está financiada por los tres gobiernos sin que se haya establecido un monto, ni la parte que se debe dedicar al trilingüismo. Desde 1994, cada país contribuye con tres millones de dólares, lo que significa que, en términos reales, el presupuesto se reduce cada año. 
En realidad, no existen agentes que se dediquen exclusivamente a interpretar y traducir. La Comisión contrata, en función de sus necesidades, a traductores e intérpretes independientes. Emplea, sin embargo, a tres redactores para los tres idiomas, de los cincuenta empleados del total en la sede en Montréal. Se trata de una estructura mucho más ligera, proporcionalmente, al número de funcionarios y de idiomas oficiales que en el caso europeo, en el cual aproximadamente un tercio de los miles de funcionarios de más alto nivel se dedican a tareas directamente relacionadas con la traducción e interpretación. Los juristas podrán debatir si existe una obligación jurídica formal para que todo se traduzca a los tres idiomas oficiales. No es el caso, pero tampoco se puede afirmar que el trilingüismo está ausente de las preocupaciones de la Comisión. Está totalmente respetado de manera formal. Para las reuniones informales, aunque el inglés sea utilizado casi exclusivamente, se hace un esfuerzo importante, en particular en favor del francés, que sólo se habla por un dos por ciento de la población de la región. Si los documentos de trabajo están casi exclusivamente en inglés, los comunicados de prensa y los resúmenes ejecutivos se traducen a los tres idiomas. Este esfuerzo responde a las presiones políticas de Canadá, que de esta manera evita problemas internos con una de sus provincias y afirma su identidad frente a Estados Unidos. Por la complejidad del sistema federal canadiense, Québec, así como Manitoba y Alberta, firmaron el TLCAN, al lado del gobierno canadiense.

\section{Conclusiones}

Los principios que guían implícitamente el régimen lingüístico del TLCAN, el respeto de la soberanía de los Estados firmatarios para el reconocimiento de los tres idiomas oficiales, así como la economía y la flexibilidad para el funcionamiento interno, no son apolíticos.

Los objetivos explícitamente económicos del Acuerdo no eximen ni a los políticos ni a los académicos de una reflexión sobre el estatuto lingüístico del bloque de América del Norte. Después de todo, el idioma es un instrumento básico de comunicación que garantiza la aplicación 
STÉPHAN SBERRO

cabal del Tratado. No se necesita indagar muy profundamente para encontrar un ejemplo, el mero hecho de que se llame tratado en español, "accord" en francés y "agreement" en inglés, tiene consecuencias jurídicas y, por ende, políticas importantes.

Los cambios económicos, sociales y políticos que experimentó México desde la firma del Tratado comprueban que éste tiene un significado político. Para México, más que para sus dos socios, el TLCAN significaba consolidar la democracia y la economía liberal de mercado. El TLCAN permitió ratificar la decisión que se venía tomando con la adhesión al GATT, actualmente a la OMC y a la OCDE, de ligar su destino al de sus principales socios económicos, Estados Unidos, la Unión Europea, Canadá y Japón.

De haber manifestado explícitamente este propósito político, el resultado de la negociación y el contenido del Acuerdo hubieran podido ser distintos desde el principio, en particular en materia lingüística. Después de todo, el MERCOSUR, que sí manifestó su objetivo político, integró mucho mejor la dimensión lingüística, aceptando y fomentando el bilingüismo imperante en la región.

La inercia y el laissez faire, frente a la hegemonía absoluta del inglés, es también una decisión política. A lo largo de este texto hemos visto que, tanto en América del Norte como en Europa, siempre se han adoptado, políticas activas, tomando en particular dos ejemplos que nos concernían más cercanamente, los de España y de Canadá. No hemos hablado de Estados Unidos, pues este país no promueve ningún régimen lingüístico dentro del TLCAN, ya que mantener el status quo es la alternativa que más conviene a sus intereses. Tampoco adopta generalmente posiciones en favor del inglés en otros foros internacionales, pues no es necesario. Así, la aparente falta de interés de Estados Unidos se debe sólo a que, en este momento, es la actitud que mejor corresponde a sus intereses. En caso contrario, el país también propugnaría por un régimen lingüístico más claro en favor del inglés. Es fácil deducir esto a partir de las numerosas legislaciones en favor del "inglés solamente", que se han pasado en los estados de la federación. A pesar de que las minorías lingüísticas en Estados Unidos son diversas, dispersas, políticamente heterogéneas, 
y compuestas de antiguos y recientes inmigrados, que tienen muy poco en común y muestran poco interés en codificar el uso de su lengua materna y un afán de asimilación fuerte, muchos estados han percibido la necesidad de reforzar el estatuto político e institucional del inglés. Esto, sin hablar del pasado y de la erradicación política, a veces apoyada por medios legales, del neerlandés y sobre todo del alemán hasta principios del siglo XX. Este aparato legislativo nuevo puede servir sólo como en el caso de la ley pasada en Arkansas, para reafirmar la importancia histórica del inglés en función de la identidad nacional, exactamente como en el caso del francés o del español en Canadá y México, respectivamente. ${ }^{52}$ También cabe recordar la evolución del pensamiento de Samuel Huntington que mencionamos al principio de este artículo. Después de haber reflexionado sobre el choque de civilizaciones, Huntington reflexionó sobre la identidad de Estados Unidos, vislumbrando un peligro para su preservación si no se asimilaban a las minorías hispanas. ${ }^{53}$ Así, Estados Unidos dispone del aparato institucional y legal, y de las bases teóricas para desarrollar, cuando estime que es de su interés, una política lingüística para el TLCAN.

El dinamismo demográfico del español y la solidez de su implantación en el hemisferio nos ubica en una situación más confortable que los canadienses. Sin embargo, debemos permanecer vigilantes, pues ninguna situación, por cómoda que sea, perdura sin esfuerzo en las relaciones internacionales. Así, el español debe mantener el mismo estatuto, no solamente como lengua oficial, sino también como lengua de trabajo dentro del TLCAN. De no ser así, el estatus, el prestigio y el enriquecimiento de la lengua decaerían rápidamente. Varios antecedentes históricos (el occitan en Francia o el escocés en Escocia), ${ }^{54}$ así como la actual

${ }^{52}$ Sandra Del Valle, Language Rights and the Law in the United States, 2003, Clevedon, Multilingual Matters LTD, pp. 59-60.

${ }^{53}$ Samuel P. Huntington, “The Hispanic Challenge”, 2004, en Foreign Policy, núm. 141, pp. 30-45.

${ }^{54}$ No podemos explayarnos más sobre estos ejemplos. Recordemos que el occitan era igual o más prestigioso y más hablado que el francés. La pérdida progresiva de su uso oficial lo extinguió paulatinamente. Pasó lo mismo con el escocés -no confundir con el gaélico escocés; el scots es un idioma anglosajón de la misma familia del inglés-, está a punto de desparecer a pesar de que fue la lengua oficial del parlamento, de los artistas, y de la iglesia escocesa. 
experiencia española en Europa, nos llaman a esta constante vigilancia. Además, como lo hemos mencionado, más allá de preservar nuestro espacio y defender nuestros derechos, el español podría ser un instrumento útil de proyección de poder de un país que, por su tamaño e importancia económica, así como por su situación geopolítica y su herencia cultural, es una potencia emergente. México es también el mayor país hispanohablante del mundo y el pionero en la integración con la América anglosajona. Esto nos brinda un papel, una responsabilidad y oportunidades excepcionales. Hasta ahora, poco hemos hecho para aprovecharlas. No tenemos antecedentes para construir una estrategia de proyección exterior del idioma, pero, como hemos mencionado, podemos apoyarnos en dos experiencias útiles. La primera es la experiencia española para utilizar el español como instrumento de afirmación regional en la Unión Europa. México convocó la primera Cumbre Iberoamericana y dispone también de una red de centros culturales en el mundo, excepcionales para un país latinoamericano.

La segunda referencia, más relevante en el marco del TLCAN, es la de la política lingüística de Canadá como instrumento de "poder blando". La diplomacia canadiense siempre ha exhibido posturas claras en los debates internacionales sobre temas culturales, incluidos los lingüísticos. El gobierno federal canadiense, así como los gobiernos de algunas provincias, en particular Québec, se han mostrado atentos al régimen lingüístico del TLCAN y al estricto respeto al trilingüismo. Su interés es una mayor colaboración con México, ya que una mayor presencia del español garantiza una mayor posibilidad de presencia para el francés. ${ }^{55}$ Así, a pesar de sus diferencias geolingüisiticas, los intereses de México y Canadá coinciden.

Se puede hacer mucho para promover los intereses de los dos países y estrechar los lazos regionales. A quince años de su entrada en vigor, el TLCAN ha demostrado a la vez su utilidad y sus límites. Muchas voces llaman a la constitución de una verdadera comunidad norteamericana, que será uno de los debates importantes en los años venideros para la

${ }^{55}$ Entrevista con C. Dumas, subsecretario responsable de la política lingüística de la provincia de Québec, 2008. 
política exterior de México. ${ }^{56}$ El establecimiento de un verdadero régimen lingüístico, que haga comprensible y legítima a nuestra lengua a los ojos de todos sus ciudadanos, es una de las condiciones necesarias para la constitución de tal comunidad.

No es una tarea fácil. Como hemos visto, la Unión Europea debate el tema desde hace cincuenta años sin haber encontrado una solución idónea. Quizás no exista tal solución y el régimen lingüístico, como todos los temas culturales, es un proceso sometido a un debate permanente. Si los europeos no pueden ofrecernos una referencia, por lo menos nos ofrecen sus debates. En México, aún no se han abierto. México tiene mucho que ganar en desarrollar una verdadera política lingüística exterior. Es una potencia lingüística gracias al uso de un idioma internacional reconocido. España ha sabido tomar el liderazgo del uso del español con fines políticos y sigue intentando obtener un estatuto privilegiado para el idioma dentro de Europa, distinto de los idiomas con un número comparable de hablantes como el neerlandés, el polaco o el rumano, gracias a su estatuto internacional. Nuestra zona de proyección privilegiada es América del Norte. Si sabemos hacer lo mismo, puede redituar inmediatamente (el idioma es un negocio para los medios de comunicación masiva e incluso para su enseñanza), y también, a largo plazo, como trampolín para lograr una mayor influencia en otras organizaciones regionales e internacionales, incluidas las ganancias económicas y políticas que esto implica.

Finalmente, no se puede reflexionar sobre los idiomas en América del Norte sin recalcar que existe una injusticia aún más grave que el desuso del español en las negociaciones más importantes en América del Norte, pues atañe a más idiomas, a hablantes más indefensos por su

${ }^{56}$ Robert Pastor en su tesis doctoral ya había hablado de la inevitabilidad de la constitución de una comunidad norteamericana a partir del TLCAN, como lo es el caso de Europa. Véase, "L'intégration nord Américaine a la lumière de l'expérience européenne", 1996, Université de Paris III, Sorbonne Nouvelle-Institut des Hautes Etudes de l'Amérique Latine; véase también, Robert Pastor, "Towards a North Américan Community, Lessons from the Old World to the New", 2001, Institute for International Economics; y más recientemente, "The Future of North América Replacing a Bad Neighbor Policy", en Foreign Affaires, julio-agosto 2008; Mark Aspinwall, "NAFTA-ization: Regionalization and Domestic Political Adjustment in the North American Economic Area”, 2009, en Journal of Common Market Studies, vol. 47, núm. 1, pp. 1-24. 
STÉPHAN SBERRO

número, su diversidad, su dispersión y su poco poder socioeconómico. Se trata de la injusticia para los idiomas indígenas; estas "primeras naciones", como se dice en Canadá, representan un número tan pequeño $\left(0.5 \%\right.$ de la población canadiense, ${ }^{57}$ y $1.5 \%$ de la población de Estados Unidos), ${ }^{58}$ que es inconcebible darles los mismos derechos de lenguas oficiales que tienen el inglés y el francés, pero una acción de reconocimiento es posible. ${ }^{59}$ Esta injusticia y desigualdad, ${ }^{60}$ todavía más seria en Estados Unidos, es también un tema en el cual los países de América del Norte pueden cooperar. No es objeto directo de nuestro estudio, pues no tiene una vertiente internacional fuera de esta posible cooperación. Recordemos que en México, los hablantes de idiomas indígenas representan más del diez por ciento de la población y sus derechos lingüísticos son ahora reconocidos por la Constitución. Con este número, el marco institucional que ya tenemos, y sobre todo con el prestigio que gozan los idiomas indígenas hablados en México en comparación con los de los otros países de América del Norte, también podríamos ejercer un liderazgo en todo el continente en interés de nuestras poblaciones.

Seguramente el debate sobre nuestra relación con el español es amplio y no es el lugar de emprenderlo aquí. Grandes escritores latinoamericanos como Octavio Paz y Pablo Neruda, e internacionalistas postcoloniales como Walter Mignolo ya lo han hecho. Aquí he desarrollado ciertas conclusiones al respecto. Sabemos que el castellano es un idioma colonial impuesto, y no lo podemos utilizar y defender de la misma forma que España, que además tiene problemas y entornos muy distintos.

${ }^{57}$ Además, no todos utilizan su lengua de origen.

${ }^{58}$ Census 2000 brief http://www.census.gov/prod/2002pubs/c2kbr01-15.pdf

${ }^{59}$ En 1988, el Territorio del Noroeste reconoció como lenguas oficiales al chipewyan, cree, dogrib, gwich'in, inuktitut y slavey al lado del inglés y del francés. Por su parte, el gobierno de Québec excluyó de la aplicación de la ley 101 sobre el uso del francés a los idiomas cree, inuktitut y naskapi, y el derecho de sus hablantes para educar a sus hijos en sus idiomas está reconocido por la ley. Por supuesto, se trata también de responder a demandas más graves de autogobierno y autodeterminación por parte de estos pueblos. Press.

${ }^{60}$ W. Kymilicka, Liberalism, Community and Culture, 1989, New York, Oxford University 
La segunda conclusión es que, como en el caso de Estados Unidos y Canadá, aunque de manera distinta, pues México es sólo parcialmente un país construido por la inmigración europea, también es parte de nuestra herencia, como lo son los otros idiomas hablados en México. También es cierto que definir una política lingüística frente al exterior no resolverá problemas más urgentes en cuanto a la enseñanza del español y otros idiomas mexicanos, ni sobre el nivel educativo de la población. El poder de un idioma depende del poder de los que lo hablan.

Para limitarnos al propósito de este artículo, la tercera conclusión es el hecho de que el idioma español es ciertamente una ventaja subutilizada; el TLCAN es un foro adecuado para empezar a utilizarla más y el debate debe empezar lo antes posible.

En materia de política lingüística nada está asegurado. Aun los estadounidenses, y sobre todo los británicos, que a veces asumen una posición triunfalista, ${ }^{61}$ justificable, dado el dominio absoluto del inglés en las relaciones internacionales, siguen reflexionando y elaborando estrategias. Es notable la publicación, patrocinada por el British Council, ${ }^{62}$ de un informe en 2006 que emite serias dudas sobre la preeminencia del inglés en el mundo, tanto desde el punto de vista de su perennidad, como desde el interés del Reino Unido en mantener, o tener la ilusión, de esta preeminencia absoluta. Una razón más para que México se ubique en el debate que viene. La vigilancia, la imaginación y el pragmatismo son indispensables. Tanto Canadá como Estados Unidos, cada uno a su manera y en función de sus intereses, tienen políticas activas y reflexiones avanzadas sobre la mejor forma de promover sus intereses por medio de la cultura. México, como potencia mundial emergente y país estratégico en América Latina puede, sin lugar a dudas, seguir enriqueciendo la cultura mundial, pero tiene que utilizar su idioma como instrumento cultural y lingüístico para promover sus intereses.

${ }^{61}$ Christof Demont-Heinrich, “Américan Triumphalism and the 'Offensive' Defensiveness of the French as a Foil for English in U.S. Prestige Press Coverage of the Global Hegemony of English”, en Journal of Communication Inquiry, vol. 32, 2008, pp. 271-91.

${ }^{62}$ David Graddol, English Next, British Council, 2006. 
CITAM Derechos Reservados.

La reproducción total o parcial de este artículo se podrá hacer si el ITAM otorga la autorización previamente por escrito. 